\title{
ÍNDICE DE DESENVOLVIMENTO DO SETOR EXTERNO SUCROALCOOLEIRO BRASILEIRO: UMA ANÁLISE DE 1999 A $2007^{1}$
}

\author{
Rubiane Daniele Cardoso ${ }^{2}$ \\ Kátia Fabiane Rodrigues ${ }^{3}$ \\ Vanessa de Souza Dahmer ${ }^{4}$ \\ Pery Francisco Assis Shikida
}

\begin{abstract}
Resumo: Esta pesquisa objetivou verificar o desempenho do setor externo sucroalcooleiro brasileiro, de 1999 a 2007. Foram utilizados dois indicadores de comércio internacional, quais sejam, o Índice de Abertura de Comércio $\left(O_{i}\right)$ e o Índice de Desenvolvimento do Setor Externo $\left(S X_{i}\right)$. Como corolário, foi constatado que o grau de abertura do comércio, no período, obteve níveis intermediários. O setor sucroalcooleiro apresentou, em vários anos, alta vulnerabilidade, no entanto, a análise demonstrou que o setor está procurando maior inserção no comércio internacional, porquanto apresentou tendência crescente no volume de comércio.
\end{abstract}

Palavras-chave: sucroalcooleiro, índices de desempenho, comércio internacional, Brasil.

\section{Introdução}

No Brasil, a cana-de-açúcar ocupa cerca de 7 milhões de hectares ou cerca de $2 \%$ de toda a terra arável do país, que é o maior produtor mundial, seguido por Índia, Tailândia e Austrália. As regiões de cultivo são Sudeste, Centro-Oeste, Sul e Nordeste, com duas safras por ano.

Recebido em: 16/09/09; Aceito em: 21/12/09.

2 Economista pela Unioeste/Campus- Toledo. Mestranda em Desenvolvimento Regional e Agronegócio Unioeste/Campus - Toledo.

E-mail: rubicardoso@yahoo.com.br.

3 Economista pela Unioeste/Campus - Toledo. Mestranda em Desenvolvimento Regional e Agronegócio Unioeste/Campus - Toledo. E-mail: kafrodrigues@yahoo.com.br.

4 Economista pela Unioeste/Campus - Toledo. Mestranda em Desenvolvimento Regional e Agronegócio Unioeste/Campus - Toledo. E-mail: nessadahmer@yahoo.com.br.

5 Doutor em Economia Aplicada pela ESALQ/USP. Professor Associado da Unioeste/Campus - Toledo.

E-mail: peryshikida@hotmail.com 
Portanto, durante todo o ano, o Brasil produz açúcar e etanol para os mercados interno e externo (UNIÃO DA INDÚSTRIA DE CANADE-AÇÚCAR - UNICA, 2009).

Conforme Shikida (1998), com a implementação do Programa Nacional do Álcool (PROÁLCOOL), a agroindústria canavieira passou por três fases distintas de desempenho. A primeira (1975 a 1979) foi caracterizada pelo crescimento moderado, na qual prevalecia o modelo subvencionista como padrão de sobrevivência, destacando a produção de álcool anidro; a segunda (1980 a 1985), pela expansão acelerada, destacando a produção de álcool hidratado; e a terceira (1986 a 1995), pela desaceleração e pela crise do Programa, e o setor, como um todo, entrou num processo de desregulamentação estatal (a partir de 1990, com a extinção do Instituto do Açúcar e do Álcool - IAA). Contudo, a redução da ação estatal deuse em ritmo gradual, iniciando com a liberação das exportações de seus produtos, passando por liberações dos preços do açúcar de vários tipos e do etanol anidro e foi concluída com a liberação dos últimos preços, que ainda eram mantidos sob controle oficial (cana, açúcar standard e etanol hidratado) (ALVES, 2002). Nesse caso, um novo modelo de gerenciamento que fosse mais adequado aos princípios do Estado moderno, indutor da melhoria da qualidade, tornou-se necessário.

Destarte, considerando a evolução da agroindústria canavieira no Brasil ${ }^{6}$, pode-se dizer que, depois da desregulamentação setorial, este é o momento de expansão para o setor, posto que contribui para ampliar a competitividade setorial. Isso porque, com o fim do controle estatal, as usinas e destilarias tiveram que se adaptar ao livre mercado e caminhar sem os incentivos, os subsídios e a coordenação do Estado. Nesse contexto, os atores passaram a procurar desenvolver competências, visando à geração de vantagens técnicas que lhes permitissem se manter na atividade, de maneira sustentável (PAULILLO et al., 2007).

6 Para uma revisão de literatura sobre a evolução da agroindústria canavieira brasileira ver, dentre outros: Szmrecsányi (1979); Moraes e Shikida (2002); Buainain e Batalha (2006); Unica (2007); Neves e Conejero (2007); e Goes et al. (2008). 
Rubiane Daniele Cardoso, Kátia Fabiane Rodrigues,

Vanessa de Souza Dahmer \& Pery Francisco Assis Shikida

Cumpre dizer que "um regime de maior liberdade de atuação deverá aumentar a participação no mercado das empresas mais eficientes que a média e, com isso, tornar o setor mais rentável" (FERNANDES e COELHO, 1996, p.154). Embora a agroindústria canavieira nacional seja tecnicamente qualificada e tenha menores custos de produção do mundo, além de contar com bom potencial para aumento da produção, faz-se mister verificar o desempenho do setor externo sucroalcooleiro brasileiro. Assim, o foco deste estudo está em analisar, por meio dos indicadores de comércio internacional [Índice de Abertura de Comércio $\left(O_{i}\right)$ e Índice de Desenvolvimento do Setor Externo $\left(S X_{i}\right)$ ], o desempenho do setor externo sucroalcooleiro, no período de 1999 a 2007. Não obstante, ao estudar o setor em epígrafe, procurar-se-á constatar elementos que o caracterize, obtendo informações adicionais que poderão servir de subsídios para futuras tomadas de decisões.

Isto posto, este artigo encontra-se dividido em quatro seções, incluída esta introdução. Na seção seguinte, é exposta a metodologia que norteia a presente pesquisa, bem como os principais fatos ocorridos no cenário de análise. Na terceira, são apresentados os resultados e as discussões. As considerações finais, na quarta seção, sintetizam esta pesquisa.

\section{Metodologia}

Para contemplar o escopo deste estudo, utilizaram-se os índices que medem a abertura comercial (subseção 2.1.) e o desempenho do setor externo (subseção 2.2.), na tentativa de avaliar o contexto internacional deste e os avanços na inserção no mercado global. Primeiramente, abordou-se o Índice de Abertura de Comércio $\left(O_{i}\right)$, proposto por Edwards (1998), que analisa a relação do Volume de Comércio (VC) (exportação somada à importação) de um setor (podendo ser de um país) com o Produto Interno Bruto $(P I B)$ - nesse caso, considera-se o PIB do setor sucroalcooleiro (mas pode ser de um país), mensurando o nível de liberalização do comércio. Posteriormente, abordou-se o índice para o estudo do comércio internacional, de Ruiz (2004) - denominado Índice 
de Desenvolvimento do Setor Externo $\left(S X_{i}\right)$, que complementa a análise do primeiro, pois mede a liberalização do comércio e a mobilidade de investimentos estrangeiros, simultaneamente. É importante destacar que os índices, citados anteriormente, ainda não foram aplicados a nenhum setor produtivo da economia brasileira, o que ressalta o ineditismo desta pesquisa.

Outrossim, foram explorados os dados secundários extraídos das referências que tratam da questão internacional do setor sucroalcooleiro brasileiro. Procurou-se avaliar o seu desempenho a partir da análise de uma série de dados (subseção 2.3.), obtidos em fontes como a União da Indústria de Cana-de-açúcar - UNICA (2009), a Companhia Nacional de Abastecimento - CONAB (2009) e o Banco Central do Brasil BACEN (2008).

\subsection{O Índice de Abertura de Comércio $\left(O_{i}\right)$}

O $O_{i}$ estuda a relação entre o $V C$ - que seria a soma das exportações e importações $(X+M)$ - e o PIB (EDWARDS, 1998). Nesse sentido, o $O_{i}$ mede o nível de liberalização do comércio, bem como a orientação da política comercial. Seu objetivo é apontar qual a real participação do setor externo no produto doméstico, ou seja, quão aberta ao mercado mundial está uma economia. Seu valor varia de 0 a $100 \%$, ou seja, quanto mais perto de $100 \%$, maior o grau de abertura da economia analisada. Este índice é definido por:

$$
O_{i}=\frac{(X+M)}{P I B} \times 100 \%
$$

2.2. O Índice de Desenvolvimento do Setor Externo $\left(S X_{i}\right)$

O $S X_{i}$ está também ligado ao Índice de Abertura Comercial, $O_{i}$. A 
diferença entre esses dois indicadores é o fato de ao $S X_{i}$ acrescentar a taxa de crescimento do comércio, representada pela Taxa de Variação do $V C(\Delta V C=$ Taxa de Variação da Exportação mais Taxa de Variação da Importação) e a Taxa de Variação do Investimento Estrangeiro Direto $(\triangle I E D)$. Elucidando melhor, o $V C$ é igual à soma do fluxo de exportação (Free On Board - FOB) mais o fluxo de importação (Cost Insurance and Freight - CIF). O investimento é representado pela variação do montante entre os anos a serem analisados. $\mathrm{O}$ cálculo do $S X_{i}$, segundo Ruiz (2004), requer quatro passos, quais sejam:

$1^{\circ}$ passo - Taxa de Variação do Volume de Comércio $(\Delta V C)$ :

$$
\Delta V C=\frac{(X+M)_{n+1}-(X+M)_{n}}{(X+M)_{n}} .
$$

$2^{\circ}$ passo - Taxa de Variação do Investimento Estrangeiro Direto ( $\left.\triangle I E D\right)$ :

$$
\Delta I E D=\frac{(I E D)_{n+1}-(I E D)_{n}}{(I E D)_{n}} .
$$

$3^{\circ}$ passo - Taxa de Variação do Produto Interno Bruto $(\triangle P I B)$ :

$$
\Delta P I B=\frac{(P I B)_{n+1}-(P I B)_{n}}{(P I B)_{n}} .
$$

$4^{\circ}$ passo - $S X_{i}$ é igual à soma da $\triangle V C$ e da $\triangle I E D$ dividido pela $\triangle P I B$, ou seja,

$$
S X_{i}=\frac{(\Delta V C+\Delta I E D)}{\Delta P I B} \times 100 \%
$$




\subsubsection{Aspectos da análise do Índice de Desenvolvimento do Setor Externo $\left(S X_{i}\right)$}

Ao explicitar alguns pontos pertinentes a esta discussão, são separadas as três categorias de vulnerabilidade da análise do $S X_{i}$ :

$\left.1^{\circ}\right)$ A alta vulnerabilidade ocorrerá sempre que a Variável Principal do Comércio $\left(E S_{i}\right)^{7}$ e a $\triangle P I B$ estiverem localizadas nos seguintes parâmetros $\left(+E S_{i} /+\Delta P I B\right)$ ou $\left(-E S_{i} /-\Delta P I B\right)$ ou $\left(E S_{i}=0 / \Delta P I B=0\right)$, então, o $S X_{i}$ poderá ser classificado dentro da categoria de alta vulnerabilidade . A alta vulnerabilidade indica que a $E S_{i}$ e o $P I B$ possuem mudanças na mesma direção e que podem estar fortemente ligados.

$\left.2^{\circ}\right)$ A vulnerabilidade normal acontecerá sempre que a $E S_{i}$ e a $\triangle P I B$ estiverem localizadas dentro dos parâmetros $\left(+E S_{i} /-\triangle P I B\right)$ ou $\left(+E S_{i} /\right.$ $\triangle P I B=0)$, então, o $S X_{i}$ poderá ser classificado dentro da categoria de vulnerabilidade normal. A categoria de vulnerabilidade normal pode indicar que a $E S_{i}$ cresce mais rapidamente que o $P I B$, o que demonstra que, apesar de o setor externo depender da tendência do comércio mundial, este não afeta, de maneira significativa, o PIB.

$\left.3^{\circ}\right)$ Haverá baixa vulnerabilidade sempre que a $E S_{i}$ e a $\triangle P I B$ estiverem localizadas dentro dos parâmetros $\left(-E S_{i} /+\Delta P I B\right)$ ou $\left(-E S_{i} / \Delta P I B=0\right)$ ou $\left(E S_{i}=0 /+\Delta P I B\right)$ ou $\left(E S_{i}=0 /-\Delta P I B\right)$; então, o $S X_{i}$ poderá ser classificado dentro da categoria de baixa vulnerabilidade. A categoria de baixa vulnerabilidade pode mostrar como a $E S_{i}$ cresce lentamente em relação ao crescimento do $P I B$, o que mostrará que o setor externo não é o fator principal que afeta o crescimento do $P I B$ de qualquer setor.

Sendo a $E S i=\Delta V C$ (variação do Volume de Comércio $)+\Delta \mathrm{IED}$ (variação do Investimento Estrangeiro Direto). 
Rubiane Daniele Cardoso, Kátia Fabiane Rodrigues,

Vanessa de Souza Dahmer \& Pery Francisco Assis Shikida

\subsection{Principais fatos ocorridos no cenário de análise}

Antes de pormenorizar os resultados dos indicadores do desempenho do comércio internacional do setor sucroalcooleiro, é necessário destacar alguns dos fatos importantes que ocorreram neste cenário. A agroindústria canavieira vivenciou dois momentos importantes, de 1999 a 2007. O primeiro, na década de 90, com a extinção do IAA, portanto, o início da desregulamentação do setor. No ano de 1999, recrudesce o regime cambial flexível no Brasil.

Segundo Barros e Moraes (2002), a desregulamentação da agroindústria canavieira alterou o ambiente institucional, o que trouxe a necessidade de articulação e coordenação entre os agentes da cadeia produtiva, ocasionando mudanças significativas nos papeis que, anteriormente, o Estado assumia. Citam-se aqui, por exemplo, as funções de planejamento e comercialização. Já a política de liberalização do câmbio acarretou a desvalorização da moeda brasileira, elevando a competitividade do mercado interno e favorecendo, entre outros, o setor exportador de açúcar (AGÊNCIA DE INFORMAÇÃO EMBRAPA - CANA-DEAÇÚCAR, 2009).

O Brasil, no tocante ao mercado, tem a característica de tomador de preços, pois suas exportações não determinam os preços do açúcar no mercado internacional. Alguns fatores que colocam o país nessa posição são a força de outros grandes exportadores, as políticas protecionistas e a substituição do açúcar por outros produtos similares.

Nesse contexto setorial sucroalcooleiro, as unidades produtoras de álcool apostaram nas montadoras de veículos bicombustíveis e na tendência do crescimento do preço mundial do petróleo. Já no médio prazo, as expectativas dos produtores de etanol estão na consolidação do mercado externo. No período de 2004/2005, o Brasil exportou 2,4 bilhões de litros de álcool (AGÊNCIA DE INFORMAÇÃO EMBRAPA - CANA-DEAÇÚCAR, 2009). 
No ambiente político, como oportunidades para o setor sucroalcooleiro têm-se uma possível reaproximação com os Estados Unidos, mediante redução tarifária; o uso de etanol em outros países; e a redução do ICMS dos estados do Brasil, o que influencia o preço do álcool. Ao revés, as ameaças podem ocorrer com o levantamento de barreiras tarifárias e ambientais, com a padronização visando à exportação e com as legislações trabalhistas e ambientais. No ambiente econômico, algumas das oportunidades são o crescimento da frota dos veículos flex, especialmente no Brasil; a exportação da tecnologia e a expertise na área agroindustrial canavieira; o aumento do consumo de açúcar; a queda do risco Brasil; as futuras quebras de produção em outros países produtores; e a geração de tributos pelo setor. Nesse cenário, as ameaças são decorrentes do surgimento de novos concorrentes, como o Caribe e a África, da capacidade produtiva insuficiente, dos custos dos insumos e da concentração de venda de etanol a poucos e a grandes mercados, como os Estados Unidos (NEVES e CONEJERO, 2007).

Neste panorama, a UNICA (2009) aponta que a safra 2008/2009 foi recorde, atingindo um montante de 570 milhões de toneladas de cana, com uma área plantada de 8,5 milhões de hectares. O setor sucroalcooleiro aferiu, em 2008, um PIB de US $\$ 28,15$ bilhões, o que equivale a cerca de $2 \%$ do PIB nacional. Além disso, estima-se que o setor pagou, em 2008, o montante de US\$ 9,86 bilhões de impostos sobre o faturamento. O setor empregou 1,2 milhão de trabalhadores formais em 2008 - 2,15\% dos postos de trabalho no Brasil com carteira assinada.

Ao longo de 2008, o preço da cana-de-açúcar sofreu pequenas oscilações. Em maio de 2008, o valor do $\mathrm{ATR}^{8}$ era de $\mathrm{R} \$ 0,2538$; em junho diminuiu para $\mathrm{R} \$ 0,2466$; e em meados de julho até dezembro do corrente ano, o preço teve melhoras, passando de $\mathrm{R} \$ 0,2470$ para $\mathrm{R} \$ 0,2653$ (COOPERATIVA DOS PLANTADORES DE CANA DA ZONA DE GUARIBA - COPLANA, 2009).

8 Açúcar Total Recuperável consiste na quantidade de açúcar presente na matéria-prima, extraída das perdas no processo de transformação industrial, e nos preços do açúcar e do etanol vendidos pelas usinas nos mercados interno e externo. Sobre isto, ver UNICA (2007 e 2009). 
Rubiane Daniele Cardoso, Kátia Fabiane Rodrigues,

Vanessa de Souza Dahmer \& Pery Francisco Assis Shikida

De acordo com a COPLANA (2009), o Brasil teve expansão nas exportações de etanol em 2008 - passaram de 3,5 bilhões de litros, em 2007, para 5,1 bilhões, em 2008. Dentre os fatores que contribuíram para esse crescimento nas exportações, destacam-se as altas do preço do barril do petróleo, por seguidos meses, com valores superiores a US\$ 100, além da quebra da safra de milho nos Estados Unidos. Mesmo com restrições tarifárias, os Estados Unidos continuam sendo os maiores importadores de etanol do Brasil (importou 1,52 bilhões de litros). A União Européia importou, em 2008, o equivalente a 1,47 bilhão de litros.

O prognóstico para safra 2009, levantado pela CONAB (2009) em setembro de 2009, indica que o volume total de cana a ser processado pelo setor deverá atingir um montante de 629 milhões de toneladas, representando um adicional de 10,35\% do obtido na última safra.

Para os produtos derivados da cana-de-açúcar, essa safra apresenta tendência de expansão mais acentuada para o açúcar. Dessa forma, a produção estimada de açúcar para o país deverá ser de 36,7 milhões de toneladas, um crescimento de $18,23 \%$. Já para o álcool, o estudo aponta um crescimento de 1,64\%, devendo alcançar 27,96 milhões de litros em 2009 (CONAB, 2009).

O diferencial de 2008, em relação a 2007, foi o mix da produção de açúcar e de álcool, já que a preferência das usinas era pela produção de açúcar, haja vista que, no momento, esta remunerava melhor. Nesse sentido, segundo dados do Centro de Estudos Avançados em Economia Aplicada - CEPEA (2009), no primeiro semestre de 2009, o açúcar representou o produto de maior atratividade nas exportações do agronegócio, com 24,28\%. O álcool representou baixo desempenho em níveis de preços (em Reais), com recuo acima de $15 \%$ no primeiro semestre de 2009. Assim, pode-se considerar, nesse período, que o açúcar teve grande representatividade nas exportações do agronegócio, mesmo com a crise que se instalou no segundo semestre de 2008, dada a retração da demanda internacional e dados os reflexos no desempenho insatisfatório de alguns produtos exportados (como óleo de soja, papel e celulose e carne suína). 
Tabela 1 - Exportações do setor sucroalcooleiro brasileiro - 1999 a 2007 (em bilhões de US\$ FOB)

\begin{tabular}{cccc}
\hline Ano & $\begin{array}{c}\text { Exportação de } \\
\text { açúcar }\end{array}$ & $\begin{array}{c}\text { Exportação de } \\
\text { álcool total }\end{array}$ & Total = VC \\
\hline 1999 & $1.910,70$ & 65,85 & $1.976,5$ \\
2000 & $1.199,11$ & 34,79 & $1.233,9$ \\
2001 & $2.277,51$ & 92,15 & $2.369,7$ \\
2002 & $2.093,64$ & 169,15 & $2.262,8$ \\
2003 & $2.140,00$ & 157,96 & $2.298,0$ \\
2004 & $2.640,23$ & 497,74 & $3.138,0$ \\
2005 & $3.918,83$ & 765,53 & $4.684,4$ \\
2006 & $6.166,96$ & $1.604,73$ & $7.771,7$ \\
2007 & $5.100,44$ & $1.477,65$ & $6.578,1$ \\
\hline R $\left.^{2}\right)^{9}$ & 0,80 & 0,93 & 0,83 \\
\hline Taxa Geométrica & $18,44 \%$ & $62,83 \%$ & $22,18 \%$ \\
de Crescimento $(\%)$ & 10 & &
\end{tabular}

Fonte: UNICA(2009).

Ressaltam-se, na Tabela 1, as exportações do setor sucroalcooleiro brasileiro, de 1999 a 2007 (em valores). Nota-se, ao ser calculada a Taxa Geométrica de Crescimento (TGC), que as exportações de açúcar cresceram 18,44\%, no período considerado, e que as exportações de álcool total (anidro e hidratado) cresceram 62,83\%; no total, houve um crescimento de $22,18 \%$ no $V C$.

Quanto à questão do $I E D$, observa-se que não há restrição, no Brasil, às indústrias de açúcar e etanol. A Constituição de 1988 acabou com a distinção entre investimentos de capital nacional e estrangeiro (embora existam algumas poucas exceções). Dessa forma, se a indústria for constituída de acordo com as leis brasileiras, a ela será garantido um tratamento isonômico, independentemente de qual for a origem de seu capital. Já em relação à produção da cana-de-açúcar, matéria-prima da

9 O coeficiente de determinação R2 demonstra o poder explicativo de uma equação. Quanto mais o R2 se aproximar de 1, maior será o seu poder explicativo. Para maiores considerações sobre isto, ver, Hoffmann e Vieira (1987).

10 A estimativa da Taxa Geométrica de Crescimento, calculada para todo o período, está de acordo com o método dos Mínimos Quadrados Ordinários. Sobre isto, ver Hoffmann e Vieira (1987). 
indústria, nota-se que a Lei estabelece certas limitações à participação do capital estrangeiro na aquisição e no arrendamento de propriedades rurais.

A competitividade do açúcar e do etanol no Brasil não resulta da ação do Poder Público, mas das condições de produção, organização e tecnologia excepcionalmente favoráveis em que se desenvolve. Trata-se de competitividade estrutural de uma produção exposta diretamente à concorrência internacional, seja competindo nos mercados mundiais, seja num mercado nacional cujo único instrumento de proteção é a tarifa sobre as importações, que para o açúcar corresponde à Tarifa Externa Comum (TEC) do Mercosul (16\%) e que para o etanol até inexiste, já que, desde março de 2006, está fixada em 0\%. Tais "proteções" nem de longe alcançam a que foi consolidada pelo país para os dois produtos na Organização Mundial do Comércio, de 35\% (UNICA, 2007, p. 26).

\section{Resultados e discussões}

Na Tabela 2 são apresentados os dados de Exportação, de Comércio, de $I E D$ e $P I B$ do setor sucroalcooleiro brasileiro, juntamente com suas respectivas variações nos anos de 1999 a 2007. Estes são os dados fundamentais que foram utilizados no cálculo dos índices que medem o desenvolvimento do setor no âmbito internacional. 
Tabela 2 - Dados de exportação, comércio, IED e $P I B$ do setor sucroalcooleiro brasileiro - 1999 a 2007 (em US\$)

\begin{tabular}{ccccccccc}
\hline Ano & Exportação & Cresc. Exp. & Comércio* & $\Delta$ Comércio & IED & $\Delta I E D$ & $P I B^{* *}$ & $\Delta P I B$ \\
\hline 1999 & 1.976 .549 .000 & 0,00 & 1.976 .549 .000 & 0,00 & 525.000 .000 & 0,00 & 5.575 .246 .384 & 0,00 \\
\hline 2000 & 1.233 .896 .000 & $-0,38$ & 1.233 .896 .000 & $-0,38$ & 3.647 .485 .000 & 5,95 & 5.118 .850 .175 & $-0,08$ \\
\hline 2001 & 2.369 .655 .000 & 0,92 & 2.369 .655 .000 & 0,92 & 85.550 .520 & $-0,98$ & 5.021 .965 .672 & $-0,02$ \\
\hline 2002 & 2.262 .789 .000 & $-0,05$ & 2.262 .789 .000 & $-0,05$ & 4.000 .000 & $-0,95$ & 4.954 .383 .168 & $-0,01$ \\
\hline 2003 & 2.297 .964 .000 & 0,02 & 2.297 .964 .000 & 0,02 & 4.427 .972 & 0,11 & 6.150 .046 .590 & 0,24 \\
\hline 2004 & 3.137 .967 .000 & 0,37 & 3.137 .967 .000 & 0,37 & 0 & $-1,00$ & 7.929 .575 .667 & 0,29 \\
\hline 2005 & 4.684 .357 .000 & 0,49 & 4.684 .357 .000 & 0,49 & 64.185 .491 & 0,00 & 10.514 .913 .351 & 0,33 \\
\hline 2006 & 7.771 .689 .000 & 0,66 & 7.771 .689 .000 & 0,66 & 530.264 .144 & 7,26 & 13.652 .017 .830 & 0,30 \\
\hline 2007 & 6.578 .083 .000 & $-0,15$ & 6.578 .083 .000 & $-0,15$ & 2.329 .588 .430 & 3,39 & 19.868 .766 .110 & 0,46 \\
\hline
\end{tabular}

Fonte: BACEN (2008) e UNICA (2009).

Nota: *O setor sucroalcooleiro não apresenta valores relevantes para o item importação.

**Devido à inexistência do dado, o PIB do setor foi estimado, pelos autores, com base na porcentagem que ele representa no PIB nacional (dados compilados da UNICA, 2009).

Os Índices calculados estão expostos na Tabela 3, os quais serão discutidos ao longo desta seção. Foram calculados os seguintes índices para o período de 1999 a 2007: o Índice de Abertura da Economia $\left(O_{i}\right)$ e o Índice de Desenvolvimento do Setor Externo $\left(S X_{i}\right)$ - descritos, de forma pormenorizada, no referencial metodológico deste artigo.

Conforme relatado, quanto ao $O_{i}$, este estuda a relação entre o Volume de Comércio $(X+M)$ e o $P I B$, medindo o nível da liberalização do comércio, bem como a orientação da política comercial de um país, nesse caso, de um setor. Seu objetivo seria mostrar qual a participação do setor externo no $P I B$, ou seja, quão aberto está o setor sucroalcooleiro brasileiro ao mercado internacional. Dessa forma, um valor maior para o índice significaria melhoria nas relações internacionais. 
Com vistas na maior clareza ao estudo, definiu-se, como parâmetro de análise, um intervalo de eficiência do grau de abertura. Assim, se o valor de $O_{i}$ estiver no intervalo de $\left(0 \leq O_{i}<30\right)$, será considerado como "baixo grau de abertura", se estiver no intervalo de $\left(30<O_{i}<60\right)$, "grau de abertura intermediário", e se estiver no intervalo de $\left(60 \leq O_{i} \leq 100\right)$, "alto grau de abertura" [os parâmetros foram definidos, pelos autores, com base em Shikida e Bacha (1999)].

Tabela 3 - Aplicação dos Índices de Abertura de Comércio e de Desenvolvimento do Setor Externo no setor sucroalcooleiro no Brasil - 1999 a 2007 (em \%)

\begin{tabular}{lllllllllll}
\hline Itens & 1999 & 2000 & 2001 & 2002 & 2003 & 2004 & 2005 & 2006 & 2007 & 3,23 \\
\hline$E S_{i}$ & 0,00 & 5,57 & $-0,06$ & $-1,00$ & 0,12 & $-0,63$ & 0,49 & 7,92 & Aceitável \\
\hline Performace $\left(E S_{i}\right)$ & - & Aceitável & Fraca & Fraca & Aceitável & Fraca & Aceitável & Aceitável & A \\
\hline$S X_{i}$ & - & $-6806,47$ & 296,29 & 7418,54 & 50,78 & $-219,27$ & 151,15 & 2654,79 & 711,43 \\
\hline$O_{i}$ & 35,45 & 24,10 & 47,19 & 45,67 & 37,36 & 39,57 & 44,55 & 56,93 & 33,11 \\
\hline Vuln. $\left(S X_{i}\right)$ & - & Normal & Alta & Alta & Alta & Baixa & Alta & Alta & Alta \\
\hline Nível vuln. & - & 1.2 & 2.2 & 2.2 & 1.1 & 2.1 & 1.1 & 1.1 & 1.1 \\
\hline
\end{tabular}

Fonte: Dados da pesquisa, adaptado de Ruiz (2004).

Perscrutando os dados da Tabela 3, o setor obteve o maior índice de abertura em 2006, atingindo $56 \%$, ficando próximo de ser enquadrado no intervalo de alto grau de abertura. O menor índice ocorreu em 2000 e foi de $24 \%$, enquadrado no intervalo de baixo grau de abertura. Na maioria dos anos analisados (exceto o ano de 2000), o $O_{i}$ manteve-se praticamente no intervalo de grau de abertura intermediário - com uma média de $40 \%$ (Gráfico 1). 


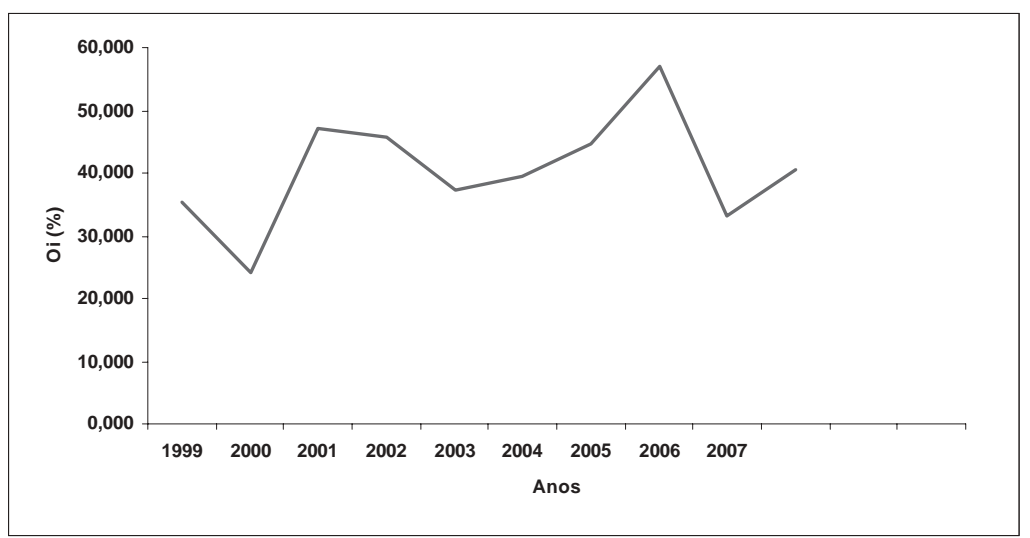

Gráfico 1 - Índice de Abertura de Comércio aplicado ao setor sucroalcooleiro brasileiro (1999-2007)

Fonte: Dados da pesquisa.

No ano de 2000, registraram-se queda considerável nas exportações de açúcar e de álcool, pequeno decréscimo no PIB e, consequentemente, baixo grau de abertura, que pode ser atribuído ao conturbado momento econômico pelo qual o mundo passava a partir do ano de 1997. A crise asiática em 1997, seguida da moratória russa em meados de 1998, trouxe consequências relevantes à economia brasileira, resultando na desvalorização do real (GIAMBIAGI e BARENBOIM, 2005).

Destarte, é importante destacar os principais destinos das exportações de açúcar do Brasil no período analisado, que foram Rússia, Nigéria, Arábia Saudita e Egito. Já as exportações de álcool se destinaram, principalmente, aos Estados Unidos, aos Países Baixos, à Jamaica e a El Salvador (UNICA, 2009). A maioria deles foi fortemente afetada pelas crises de 1997 e 1998, o que justifica a queda nas exportações brasileiras de açúcar.

É importante observar que, enquanto $O$ possui oscilações menos acentuadas (Gráfico 1), $S X$ tem um comportamento mais variado (Gráfico 2), devido à maior sensibilidade aos acontecimentos mundiais. 


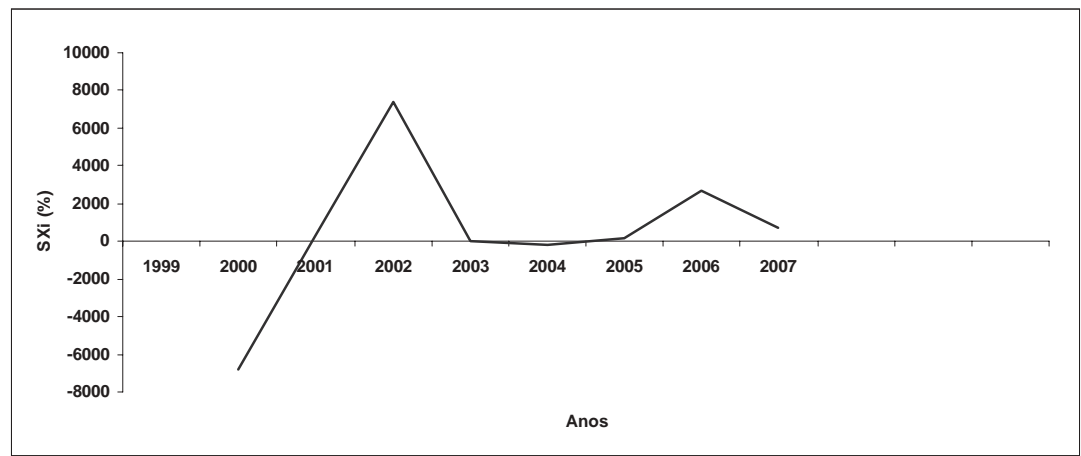

Fonte: Dados da pesquisa.

Gráfico 2 - Índice de Desenvolvimento do Setor Externo sucroalcooleiro brasileiro - 1999 a 2007

O $S X_{i}$,inserido na análise do comércio internacional por Ruiz (2004), procura mostrar, simultaneamente, o nível de liberalização do comércio e a mobilidade de investimentos (Gráfico 2). O que se percebe é que, pelo seu potencial, o setor sucroalcooleiro vem atraindo fluxos significativos de IED (cerca de US\$ 2 bilhões em 2007). Vale destacar também que, nos últimos anos, o Brasil tem sido, entre os países em desenvolvimento, o segundo maior receptor de IED, depois da China (BACEN, 2008).

$\mathrm{Na}$ maioria dos anos analisados, o setor sucroalcooleiro enquadra-se no nível de alta vulnerabilidade, ou seja, o IED, o $V C$ e o $P I B$ se movem na mesma direção, podendo estar fortemente ligados. Porém, os anos são classificados segundo o nível de vulnerabilidade. A alta vulnerabilidade é um bom sinal, desde que acompanhada de boa performance da $E S_{i}-$ Nível 1.1. Essa situação vai indicar que o setor tem forte ligação com o mercado internacional - tendo bom fluxo de IED e bom desempenho de suas exportações. No entanto, se a alta vulnerabilidade estiver atrelada ao Nível 2.2, é sinal de que, embora o setor tivesse forte ligação com o mercado internacional, os desempenhos serão negativos, inclusive do $P I B$ e da $E S_{i}$.

Observa-se, no Gráfico 2, que o ano de 2002 apresentou grande oscilação positiva, devido a variações negativas no $V C$, no $I E D$ e no $P I B$, o que 
resultou em fraca performance da $E S_{i}$ e em alta vulnerabilidade para o setor. Esse caso indica uma situação negativa, já que se enquadra no Nível 2.2.

Em 2003, o IED teve pequena variação positiva. As exportações também cresceram, juntamente com o PIB. Neste ano, o setor teve alta vulnerabilidade, Nível 1.1, e performance aceitável para $E S_{i}$. O fluxo de $I E D$ no setor foi direcionado, exclusivamente, para a produção de álcool.

Outro que merece destaque é o ano de 2004, no qual o setor apresentou Nível 2.1, ou seja, de baixa vulnerabilidade, o que mostra que o IED e o $V C$ cresceram mais lentamente em relação ao $P I B$ e, consequentemente, o setor externo não foi, nesse período, fator relevante para afetar o PIB. Isso encontra explicação no fato de que, nesse ano, não foi registrado nenhum novo ingresso de $I E D$. Uma possível explicação para a não entrada de IED no setor sucroalcooleiro, em 2004, foi o direcionamento de ingressos de $I E D$ a outros subsetores da indústria, principalmente na fabricação de produtos alimentícios e bebidas, que aumentou de 409 milhões de dólares, em 2003, para mais de 5,3 bilhões de dólares, em 2004 (BACEN, 2008).

É importante ressaltar que nos últimos anos da análise, 2005 a 2007, a vulnerabilidade se manteve no Nível 1.1, o que indica que o IED, o $V C$ e o PIB se moveram na mesma direção, podendo estar fortemente ligados. Além disso, a $E S_{i}$ teve performance aceitável, ou seja, o setor teve forte ligação com o mercado internacional - tendo bom fluxo de IED e bom desempenho nas suas exportações.

Para melhor compreensão do nível de vulnerabilidade, são apresentados os gráficos de variações do $P I B$ e da $E S_{i}$. O Gráfico 3 apresenta as variações do $P I B$, para o período de análise, e o Gráfico 4 mostra os valores da $E S_{i}$. 


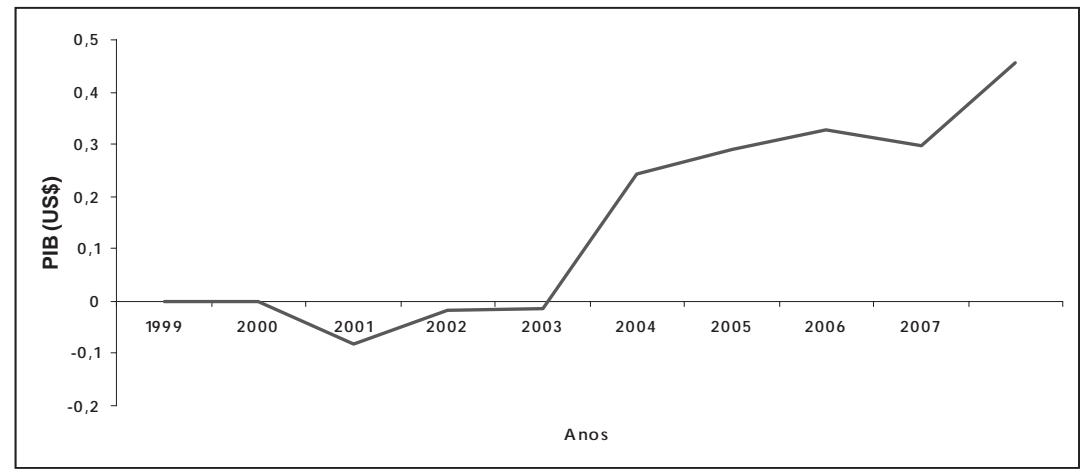

Fonte: Dados da pesquisa.

Gráfico 3 - Variações do PIB do setor externo sucroalcooleiro brasileiro - 1999 a 2007

No ano 2000, o setor apresentou um nível de vulnerabilidade normal Nível 1.2, o que mostra que o IED e o $V C$ cresceram mais rápido que o $P I B$, devido ao grande aumento no $I E D$, principalmente nas usinas de açúcar (MORAES e SHIKIDA, 2002). Então, a performance da $E S_{i}$ foi aceitável.

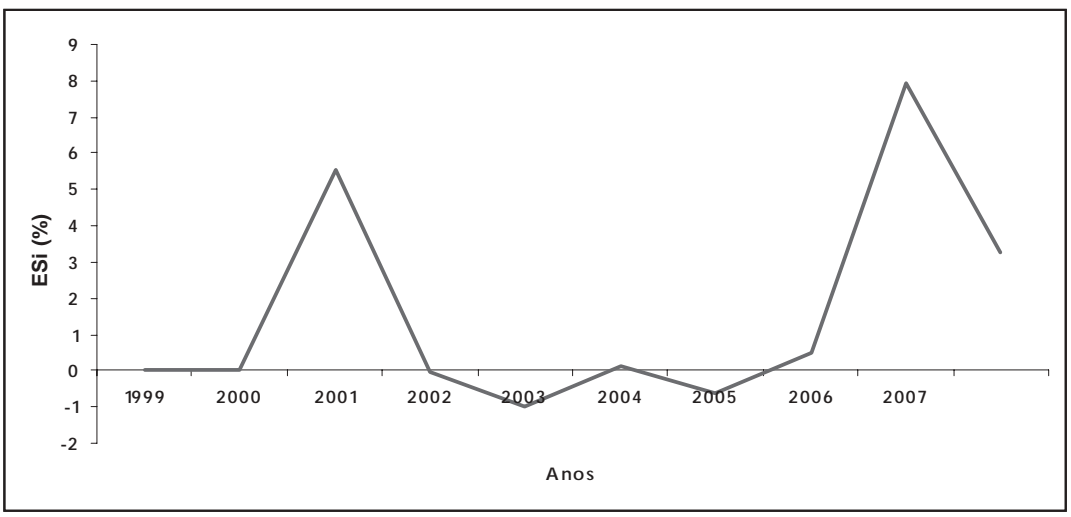

Fonte: Dados da pesquisa.

Gráfico 4 - Variações da $E S_{i}$ do setor externo sucroalcooleiro brasileiro - 1999 a 2007 
É importante mencionar a performance da $E S_{i}$ no ano de 2001, que se apresentou fraca devido à grande variação negativa no IED, que passou de cerca de mais de 3,6 bilhões de dólares, em 2000, para pouco mais de 85 milhões de dólares, em 2001, uma queda de 4151\%. A partir de 2001, o ingresso de $I E D$ declinou ainda mais, chegando a 4 milhões de dólares em 2002 e pouco mais deste valor em 2003 (4,4 milhões de dólares).

O capital estrangeiro sempre teve presença marcante na história do setor sucroalcooleiro brasileiro. Em seu auge, ele foi essencial à tentativa do Império de reestruturar a produção na segunda metade do século XIX, que culminou na criação dos engenhos centrais. A chegada das usinas modificou o panorama do IED no setor, que se estendeu, com discrição, até a segunda metade do século XX. Depois de quase meio século, o capital estrangeiro voltou revigorado, aproveitando-se das oportunidades abertas pela desregulamentação setorial, iniciada na década de 90 , e pela crescente demanda mundial de bicombustíveis eficientes (SZMRECSÁNYI e RAMOS, 2002).

No geral, verificou-se aumento significativo do IED no setor sucroalcooleiro, entre 1999 e 2007 . O valor total de $I E D$, no período, foi de cerca de US\$ 7.190 bilhões, resultando numa média anual de US\$ 899 milhões, com destaque para o ingresso, em 2000, de mais de 3,6 bilhões de dólares no setor de usinas de açúcar e de álcool. Embora o primeiro registro de capital estrangeiro no setor tenha sido em 1999, no valor de 500 milhões de dólares, o valor do ano 2000 é bem expressivo (GUEDES e GIANOTTI, 2009).

Corroborando a discussão, apresenta-se a descrição do IED, de 1999 a 2007, na Tabela 4. Verificou-se que, até 2001, os investimentos eram inteiramente voltados para a produção de açúcar; nos anos de 2002 e 2003, observam-se investimentos somente na produção de álcool; e a partir de 2005, os investimentos ocorrem em ambos os segmentos. $\mathrm{O}$ que deve ser destacado é que, a partir de 2002, houve rápido crescimento dos investimentos estrangeiros na produção de álcool, que passaram de US\$ 4 milhões, em 2002, para mais de US\$ 1 bilhão, em 2007. Esse 
Rubiane Daniele Cardoso, Kátia Fabiane Rodrigues,

Vanessa de Souza Dahmer \& Pery Francisco Assis Shikida

aumento de mais de $37.096 \%$ evidencia a importância deste setor e do Brasil no nicho de mercado de energia renovável e o interesse despertado por ele no investidor estrangeiro.

[...] O interesse de grupos internacionais pela produção de etanol no Brasil é crescente. [...] O ano de 2007 foi quente e materializou as perspectivas do mercado de etanol. [...] O Brasil espelha o que acontece no mundo. Há um grande interesse por empresas de energia renovável. No exterior existe subsídio do governo para financiar as operações. Aqui no Brasil o mercado é livre e o negócio é mais rentável (ALMEIDA, 2008, p. 30).

Tabela 4 - Fluxo de IED no setor sucroalcooleiro brasileiro - 1999 a 2007 (em US\$)

\begin{tabular}{ccc}
\hline Ano & Investimento (IED) & Descrição \\
\hline 1999 & $25.000 .000,00$ & Refino e moagem de açúcar \\
\hline 1999 & $500.000 .000,00$ & Usinas de açúcar \\
\hline 2000 & $10.000 .000,00$ & Refino e moagem de açúcar \\
\hline 2000 & $3.637 .485 .000,00$ & Usinas de açúcar \\
\hline 2001 & $85.550 .520,00$ & Usinas de açúcar \\
\hline 2002 & $4.000 .000,00$ & Produção de álcool \\
\hline 2003 & $4.427 .972,00$ & Produção de álcool \\
\hline 2005 & $7.063 .779,37$ & Produção de álcool \\
\hline 2005 & $57.121 .712,52$ & Usinas de açúcar \\
\hline 2006 & $38.500 .000,00$ & Refino e moagem de açúcar \\
\hline 2006 & $257.883 .203,40$ & Produção de álcool \\
\hline 2006 & $233.880 .941,23$ & Usinas de açúcar \\
\hline 2007 & $1.487 .847 .294,50$ & Produção de álcool \\
\hline 2007 & $841.741 .135,62$ & Fabricação de açúcar bruto \\
\hline
\end{tabular}

Fonte: BACEN (2008).

Nota: No ano de 2004, não foi registrado nenhum fluxo de IED no setor sucroalcooleiro do país. 
De modo geral, observa-se presença de capitais estrangeiros tanto na produção de açúcar quanto na de álcool, o que indica tendência de o IED confirmar a lógica da indústria nacional sucroalcooleira, ou seja, de orientar sua produção de açúcar preferencialmente para o mercado externo e de levar a produção de álcool para este mercado, embora sua orientação seja, no momento, de atendimento da demanda doméstica (no tocante ao comércio exterior, o Brasil exportou, em 2008, aproximadamente 20 milhões de toneladas de açúcar e 5 milhões de $\mathrm{m}^{3}$ de álcool etílico, representando, respectivamente, $62,8 \%$ e $22,8 \%$ da oferta doméstica de açúcar e álcool).

Isto posto, é interessante resumir os principais resultados encontrados na pesquisa, conforme a síntese no Quadro 1.

Quadro 1 - Síntese dos principais resultados da pesquisa

\begin{tabular}{|l|l|}
\hline Ano & Principais conclusões \\
\hline 1999 & Grau de abertura intermediário. \\
\hline 2000 & $\begin{array}{l}\text { Baixo grau de abertura. Queda nas exportações. Aumento de } I E D \text { nas usinas de } \\
\text { açúcar. Vulnerabilidade normal - Nível 1.2. }\end{array}$ \\
\hline 2001 & $\begin{array}{l}\text { Grau de abertura intermediário. O IED passou de cerca de mais de 3,6 bilhões } \\
\text { de dólares do ano anterior, para pouco mais de } 85 \text { milhões de dólares. } \\
\text { Performance fraca de } E S_{i} .\end{array}$ \\
\hline 2003 & $\begin{array}{l}\text { Grau de abertura intermediário. Ocorreram variações negativas no } V C \text {, no } I E D \\
\text { e no PIB. Fraca performance de } E s_{i} \text {. Alta vulnerabilidade - Nível 2.2. O IED } \\
\text { começa ser direcionado para a produção de álcool. }\end{array}$ \\
\hline 2004 & $\begin{array}{l}\text { arau de abertura intermediário. Performance Aceitável de } E s_{i} \text {. Vulnerabilidade } \\
\text { álcool. }\end{array}$ \\
$\begin{array}{l}\text { Grau de abertura intermediário. Não foi registrado nenhum novo ingresso de } \\
\text { Baixa vulnerabilidade - Nível 2.1. }\end{array}$ \\
\hline
\end{tabular}


Rubiane Daniele Cardoso, Kátia Fabiane Rodrigues,

Vanessa de Souza Dahmer \& Pery Francisco Assis Shikida

\begin{tabular}{|l|l|}
\hline 2005 & $\begin{array}{l}\text { Grau de abertura intermediário. Vulnerabilidade alta - Nível 1.1. Aumento do } \\
\text { IED na produção de álcool. }\end{array}$ \\
\hline 2006 & $\begin{array}{l}\text { Grau de abertura intermediário. Vulnerabilidade alta - Nível 1.1. O IED } \\
\text { direcionado a produção de álcool chega perto do valor do IED direcionado a } \\
\text { produção de açúcar. }\end{array}$ \\
\hline 2007 & $\begin{array}{l}\text { Grau de abertura intermediário. Vulnerabilidade alta - Nível 1.1. O IED } \\
\text { direcionado a produção de álcool surpreende chegando a mais de 1,4 bilhões } \\
\text { de dólares. }\end{array}$ \\
\hline
\end{tabular}

Fonte: Resultados da pesquisa.

\section{Considerações finais}

Esta pesquisa objetivou verificar o desempenho do setor externo sucroalcooleiro brasileiro, no período de 1999 a 2007. Para isso, foram utilizados dois indicadores de comércio internacional - o Índice de Abertura da Economia $\left(O_{i}\right)$ e o Índice de Desenvolvimento do Setor Externo $\left(S X_{i}\right)$. O primeiro é relevante para mensurar o nível de liberalização comercial e a tendência da política comercial, enquanto o segundo tem como função mensurar a liberalização do comércio e a mobilidade de investimentos, simultaneamente.

No que se refere à análise do $O_{i}$, constatou-se que o setor permaneceu no intervalo de grau de abertura intermediário, ou seja, entre $30 \%$ e $60 \%$, na maioria dos anos estudados. Apenas no ano 2000, o setor teve baixo grau de abertura, o que pode ser atribuído aos reflexos do conturbado momento econômico mundial da década anterior.

Quanto ao $S X_{i}$, este trouxe uma nova visão ao estudo do comércio mundial, que é de grande relevância para entender o comportamento do setor externo sucroalcooleiro do país, diante dos acontecimentos mundiais. $\mathrm{O}$ setor sucroalcooleiro teve alta vulnerabilidade, na maioria dos anos analisados, o que indica forte ligação do setor ao comércio mundial. No entanto, essa ligação é positiva quando acompanhada pelo bom 
desempenho da $E S_{i}$, o que ocorreu nos anos de 2003, 2005, 2006 e 2007. Diante desse fato, pode-se afirmar que o setor está procurando uma inserção maior no comércio internacional.

Em geral, no período analisado, o $V C$ teve tendência crescente. No decorrer dos anos, houve aumento na participação de álcool nas exportações do setor, em virtude da preocupação mundial com a energia renovável. Quanto ao IED, este teve forte participação no setor sucroalcooleiro, com destaque para o ano 2000 (foi de, aproximadamente, 3,7 bilhões de dólares). Vale ressaltar que, só a partir de 2002, a produção de álcool recebeu $I E D$, no entanto, de forma crescente e expressiva (em 2007, o ingresso de $I E D$ na produção de álcool foi $76,7 \%$, maior do que na produção de açúcar).

Por último, mas não menos importante, sugere-se que mais pesquisas sejam implementadas para pormenorizar os aspectos caracterizadores do desenvolvimento do setor externo sucroalcooleiro brasileiro, contribuindo, desse modo, para o enriquecimento do debate do setor em epígrafe.

\section{Referências}

AGÊNCIA DE INFORMAÇÃO EMBRAPA - CANA-DE-AÇÚCAR. Externo. Disponível em: <http://www.agencia.cnptia.embrapa.br/ gestor>. Acesso em: 01 de outubro de 2009.

ALMEIDA, E. P. de. Etanol verde-amarelo atrai investidores estrangeiros. Valor Econômico - Especial, São Paulo, p. 29-31, maio 2008.

ALVES, L. R. A. Transmissão de preços entre produtos do setor sucroalcooleiro do Estado de São Paulo. Piracicaba, 2002. 107p. Dissertação (M.S.) - ESALQ/USP.

BACEN. Tabulação especial de dados. [S.1.]: BACEN, 2008. 
Rubiane Daniele Cardoso, Kátia Fabiane Rodrigues,

Vanessa de Souza Dahmer \& Pery Francisco Assis Shikida

BARROS, G. S. C. de; MORAES, M. A. F. D. de. A Desregulamentação do setor sucroalcooleiro. Economia Política, São Paulo, v. 22, n. 2, p. 86, abr./jun., 2002.

BUAinain, A. M.; BATAlHA, M. O. (Coords.). Análise da competitividade das cadeias agroindustriais brasileiras: Agroenergia. São Carlos: Projeto MAPA/IICA, 2006. 119 p.

CEPEA. Exportações do agronegócio ganham fôlego no fim do semestre. Disponível em: <http://www.cepea.esalq.usp.br/macro/>. Acesso em: 01 de outubro de 2009.

CONAB. Cana-de-açúcar: safra 2009 segundo levantamento setembro/ 2009. Disponível em: 〈http://www.conab.gov.br/conabweb>. Acesso em 4 de outubro de 2009.

COPLANA. Safra da Cana. Disponível em: <http://www.coplana.com/ gxpfiles/ ws001/design/ Revista Coplana/2009/>. Acesso em: 01 de outubro de 2009.

EDWARDS, S. Openness, trade liberalization, and growth in developing countries. Journal of Economic Literature, v. 31, p. 1358-1393, 1998.

FERNANDES, E. S. L.; COELHO, S. T. (Orgs.). Perspectivas do álcool combustível no Brasil. São Paulo: USP - IEE, 1996. 166 p.

GIAMBIAGI, F.; BARENBOIM, I. Mercosul: por uma nova estratégia brasileira. Revista do BNDES, v. 12, n. 24, p. 77-110, dezembro de 2005.

GOES, T.; MARRA, R.; SILVA, G. S. Setor sucroalcooleiro no Brasil: situação atual e perspectivas. Revista de Política Agrícola, Brasília, ano XVII, n.2, p.39-51, abr./mai./jun., 2008. 
GUEDES, S. N. R.; GIANOTTI, L. E. A presença recente e algumas consequências do Investimento Estrangeiro Direto (IED) na agroindústria canavieira brasileira. Informações Econômicas, São Paulo, v.39, n.5, p. 151-161, maio de 2009.

HOFFMANN, R; VIEIRA. S. Análise de regressão: uma introdução à econometria. 2 ed. São Paulo: HUCITEC, 1987. 379 p.

MORAES, M. A. F. D. de; SHIKIDA, P. F. A. (Orgs). Agroindústria canavieira no Brasil: evolução, desenvolvimento e desafios. São Paulo: Atlas, 2002.368 p.

NEVES, M. F.; CONEJERO, M. A. Sistema agroindustrial da cana: cenários e agenda estratégica. Revista de Economia Aplicada, Ribeirão Preto, v.11, n.4, p.587-604, out./dez., 2007.

PAULILLO, L. F.; VIAN, C. E. de F.; SHIKIDA, P. F. A.; MELLO, F. T. de. Álcool combustível e biodiesel no Brasil: quo vadis? Revista de Economia e Sociologia Rural, Brasília, v.45, n.03. p.531-565, jul./set., 2007.

RUIZ, M. A. The External Sector Development Index (SX $)_{\mathrm{i}}$. Social Science Research Network. 2004. Disponível em: <http:// papers.ssrn.com/sol3/papers.cfm?abstr act $\_\mathrm{id}=673041>$. Acesso em: 18 de março de 2008.

SHIKIDA, P. F. A. A evolução diferenciada da agroindústria canavieira no Brasil de 1975 a 1995. 1. ed. Cascavel: Edunioeste, 1998. $149 \mathrm{p}$.

SHIKIDA, P. F. A.; BACHA, C. J. C. Alguns aspectos do mercado externo açucareiro e a inserção brasileira neste mercado. Revista Econômica do Nordeste, Fortaleza (CE), v.30, n.3, p.257-394, jul./set. 1999. 
Rubiane Daniele Cardoso, Kátia Fabiane Rodrigues,

Vanessa de Souza Dahmer \& Pery Francisco Assis Shikida

SZMRECSÁNYI, T. O planejamento da agroindústria canavieira do Brasil (1930-1975). São Paulo: HUCITEC/UNICAMP, 1979. 540 p.

SZMRECSÁNYI, T.; RAMOS, P. Evolução dos grupos empresariais da agroindústria canavieira paulista. Revista de História Econômica e História de Empresas, São Paulo, v. 1, p. 85-116, 2002.

UNICA. Bioetanol de cana-de-açúcar: energia para o desenvolvimento sustentável. Institucional. São Paulo: UNICA, 2009. 47 p.

Produção e uso do etanol combustível no Brasil: respostas às questões mais freqüentes. 2007. Disponível em: <www.unica.com.br〉. Acesso em: 14 de setembro de 2009.

Abstract: This research aimed to evaluate the performance of the external sector in the Brazilian sugar and ethanol industry from 1999 to 2007. Were used two indicators of international trade, the Openness Index $\left(O_{i}\right)$ and External Sector Development Index $\left(S X_{i}\right)$. As a corollary, it was found that the degree of openness of trade, in the period, had intermediate levels. The sugar and ethanol industry had several years in high vulnerability, instead, the analysis showed that the industry is looking for a greater presence in international trade, considering that showed an increasing trend in trade volume.

Key-words: brazilian sugar and ethanol, performance indices, international trade, Brazil. 
REVISTA DE ECONOMIA E AGRONEGÓCIO, VOL.7, $N^{\circ} 3$ 